\title{
Study on the determination of felodipine sample content by fluorescence method and its application
}

\author{
Yue Zhang*1, Jiang Wu${ }^{1}$, Fenghua Liu ${ }^{1}$, ChenWang ${ }^{1}$, Yuqing Cheng ${ }^{1}$, Yuguang Lv ${ }^{1}$ \\ ${ }^{1}$ College of Pharmacy, Jiamusi University, Jiamusi, China
}

\begin{abstract}
This experiment researched and constructed a complex with good fluorescence properties, which can be used to detect the content of felodipine. It provides a new and reliable method for the determination of felodipine. The actual sample of felodipine was successfully tested, and the test result was compared with the labeled content. It was proved that the content determined in this experiment was basically consistent with the standard content in the sample, and the reproducibility was good. Therefore, this method can be used to determine the content of felodipine in drugs, and even the content of felodipine in different substances.
\end{abstract}

\section{Introduction}

Felodipine is a selective dihydropyridine L-type $\mathrm{Ca}^{2+}$ channel blocker. By blocking the $\mathrm{Ca}^{2+}$ channel, the $\mathrm{Ca}^{2+}$ entering the cell is reduced, leading to the relaxation of arteriole smooth muscle, reducing peripheral resistance, and lowering blood pressure. It was first marketed in Denmark in 1988, and was developed as a sustained-release preparation in July 1991. Since the listing of felodipine sustained-release tablets in the United States, it has been widely used in clinical practice due to its good curative effect and low side effects. It is mainly used for the treatment of various types of hypertension and angina pectoris, and has achieved good results. When felodipine is used to treat renal hypertension, it can not only control blood pressure but also significantly improve renal function. It has a good blood pressure lowering effect and no rebound phenomenon after long-term drug withdrawal. Studies have shown that felodipine sustained-release tablets have a strong antihypertensive effect when used alone, and that felodipine sustained-release tablets combined with other anti-blood pressure have the advantages of high treatment compliance rate, safety, tolerance, and high compliance. ${ }^{[1-3]}$

This product is easily soluble in acetone, methanol or ethanol, but almost insoluble in water. BSC class II drugs so far, felodipine sustained-release tablets have been marketed in the United States, Canada, the European Union and other countries, among which the original research manufacturer has withdrawn from the market in the United States, and a large number of imitation companies have emerged. There are many manufacturers. There are 5 pharmaceutical companies in China that produce felodipine sustained-release tablets. Studies have shown that domestic felodipine sustained-release tablets have serious differences in quality. ${ }^{[4]}$ The 2015 Chinese Pharmacopoeia does not include Felodipine sustained-release tablets, and the domestic drug standard adopts the paddle method 200r/min to improve the detection efficiency, while the release conditions of the US Pharmacopoeia for surfactants SLS and Tween 80 are as high as $1 \%$. Severely contrary to the physiological state of the gastrointestinal tract, it is difficult to control the quality of marketed drugs due to the loose and indiscriminate test conditions. Therefore, it is particularly important to formulate strict and scientific standards. ${ }^{[5-7]}$

\section{Apparatus and materials}

\subsection{Apparatus}

Table 1 Apparatus

$\begin{array}{ccc}\begin{array}{c}\text { Precision electronic } \\ \text { balance }\end{array} & \text { FA2004 } & \begin{array}{c}\text { Shanghai Experimental } \\ \text { Instrument Factory Co., } \\ \text { Ltd. }\end{array} \\ \begin{array}{c}\text { UV-visible } \\ \text { spectrophotometer }\end{array} & \text { UV-2550 } & \text { Shimadzu Corporation } \\ \begin{array}{c}\text { Fluorescence } \\ \text { spectrophotometer }\end{array} & 970 \mathrm{CRT} & \begin{array}{c}\text { Shanghai Instrument } \\ \text { Analysis and Production } \\ \text { General Factory }\end{array} \\ \begin{array}{c}\text { Fourier transform } \\ \text { infrared } \\ \text { spectrometer }\end{array} & \begin{array}{c}\text { NEXUS- } \\ 670\end{array} & \begin{array}{c}\text { American Nicolet } \\ \text { Company }\end{array} \\ & & \end{array}$

*Correspondence Author: E-mail: yuguanglv@163.com 


\subsection{Reagents and materials}

\begin{tabular}{ccc} 
& \multicolumn{3}{c}{ Table 2 Reagents and materials } \\
$\begin{array}{c}\text { Absolute } \\
\text { ethanol }\end{array}$ & AR & $\begin{array}{c}\text { Tianjin Kaitong Chemical Reagent } \\
\text { Co., Ltd. }\end{array}$ \\
$\begin{array}{c}\text { Felodipine } \\
\begin{array}{c}\text { Tetracyanoe } \\
\text { thylene }\end{array}\end{array}$ & AR & $\begin{array}{c}\text { Xilong Chemical Co., Ltd. } \\
\text { Tianjin Yongda Chemical Reagent } \\
\text { Development Center }\end{array}$ \\
acetone & AR & Shanghai Adamas Reagent Co., Ltd.
\end{tabular}

\section{Method}

3.1 Preparation of felodipine standard solution; preparation of felodipine sample solution; preparation of tetracyanoethylene standard solution, see literature.

\subsection{System fluorescence spectrum measurement method;system ultraviolet spectrum measurement method}

After configuring the solution according to the experimental method, scan on the UV/Vis-265 spectrophotometer, take out $2.5 \mathrm{ml}$ of the fully reacted test solution in a cuvette, and use anhydrous ethanol as a calibrated UV spectrophotometer for UV characteristics Peak scanning, while taking equal amounts of felodipine solution and tetracyanoethylene solution as a control group, draw the absorption spectra of the three to determine the position of the strong absorption peak of the charge-transfer complex.

\subsection{System infrared spectrometry method}

For the preparation of the complex for infrared spectroscopy, add $5 \mathrm{ml}$ of $0.1 \mathrm{~mol} / \mathrm{L}$ felodipine-tetracyanoethylene charge transfer complex to a $50 \mathrm{~mL}$ round bottom flask, stir for $30 \mathrm{~min}$, and the solvent is under reduced pressure. The bottom is evaporated, and the remaining oily residue is finally dried with $\mathrm{CaCl}_{2}$ desiccant. The product obtained after drying was subjected to infrared spectroscopy.

\subsection{Screening of the best experimental conditions for the system}

For the selection of tetracyanoethylene dosage, the dosage of felodipine, the choice of reaction temperature, and the influence of reaction time, see the literature.

\subsection{Methodological investigation}

Specific investigation, under the experimental conditions, the fluorescence spectra of the blank solvent, the fluorescence system containing FEL standard solution, and the fluorescence system containing the same concentration of FEL sample solution were tested respectively.

Linear relationship, precise measurement of felodipine standard solutions with concentrations of 0.5 , $2.5,5.0,10.0,15.0,20.0,30.0,40.0,50\left(10^{-4} \mathrm{~mol} / \mathrm{L}\right)$, and irradiated with excitation light with a wavelength of 435 $\mathrm{nm}$ The fluorescence intensity $(\mathrm{F})$ of the system at 440 $\mathrm{nm}$, and the fluorescence intensity $\left(\mathrm{F}_{0}\right)$ of the blank control solution measured under the same conditions, and the difference $\Delta \mathrm{F}\left(\Delta \mathrm{F}=\mathrm{F}_{0}-\mathrm{F}\right)$ is calculated, $\Delta \mathrm{F}$ is the ordinate, corresponding to felodipine The concentration $\mathrm{c}$ is the abscissa for linear fitting.

Precision: Precisely absorb felodipine stock solutions of different concentrations of $0.5,3,6\left(10^{-3} \mathrm{~mol} / \mathrm{L}\right)$, and perform parallel determination in triplicate. The excitation wavelength is fixed at $435 \mathrm{~nm}$. The experimental data is counted and the relative standard deviation is calculated ( $\mathrm{RSD} \%$ ).

Accuracy, accurately draw $0.5,3,6\left(10^{-3} \mathrm{~mol} / \mathrm{L}\right) 3$ different concentrations of felodipine stock solution, 3 copies for each, for determination, the recovery rate is calculated based on the determined concentration and the actual concentration, the recovery rate $(\%)=$ Measured concentration/actual concentration $\times 100 \%$, and calculate the relative standard deviation (RSD\%) to investigate the accuracy of the method.

\subsection{Determination of sample content}

Measure the appropriate amount of felodipine sample solution, and calculate the actual content of the sample according to the best conditions and methods determined in the above experiment. Accurately measure the appropriate amount of felodipine reference substance, calculate the recovery rate by fluorescence intensity, calculate the relative standard deviation (RSD\%), and compare it with the pharmacopoeial method

\section{Results and discussion}

\subsection{Infrared spectrum of the system}

Figure 1 shows the infrared spectrum of the felodipine-tetracyanoethylene charge transfer complex. It can be seen from the figure that the complex has the strongest absorption peak at $1750 \mathrm{~cm}^{-1}$, which is caused by the stretching vibration of the ester group. The strong absorption peak at $2218 \mathrm{~cm}^{-1}$ is the stretching vibration peak of the cyano group and the stretching vibration of the benzene ring. The vibration peak appears near 1500 $\mathrm{cm}^{-1}$, and there is an absorption peak at $3431 \mathrm{~cm}^{-1}$. This is the stretching vibration of the $\mathrm{NH}$ bond. It can be concluded that the felodipine-tetracyanoethylene charge transfer complex has been synthesized. 


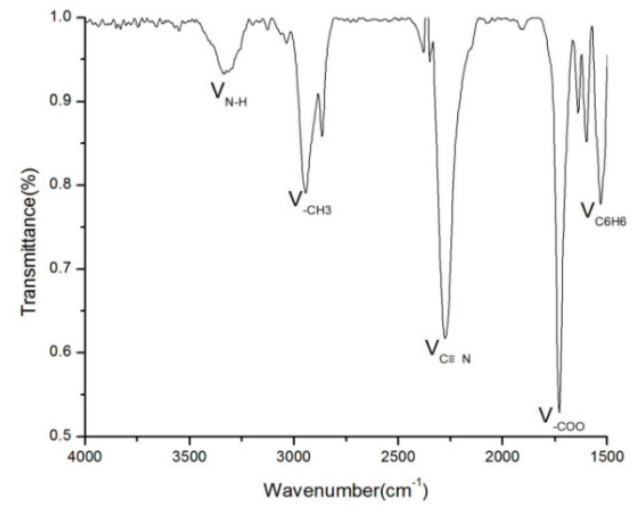

Fig. 1 Infrared spectrum of system

\subsection{Screening of the best experimental conditions}

In the case where other conditions have been optimized, we measure the effect of reaction time on the fluorescence intensity of the system. It can be seen from the figure that the fluorescence intensity of the system increases continuously with the increase of time, and tends to be stable after 40 minutes, so this experiment chooses to measure after 40 minutes of reaction.

\subsection{Methodological investigation}

According to the specificity investigation, under the experimental conditions, the blank solvent does not interfere with the main peak of the system, and the impurities do not interfere with the determination of felodipine. The method has good specificity.

Linear relationship, under optimized experimental conditions, determine the standard working curve of felodipine. As the concentration of felodipine increases, the fluorescence intensity of the system increases continuously. It can be seen that the complex can be used to determine the content of felodipine. Within a certain range, the relative fluorescence intensity of the system has a good linear relationship with the concentration. The change in fluorescence intensity $\triangle F\left(F-F_{0}\right)$ is the ordinate, and the concentration of felodipine $(\mathrm{C})$ is the abscissa. Detect the standard curve of the fluorescence system. The regression curve is: $y=5.9983 x+229.24$, the correlation coefficient is $\mathrm{R}^{2}=0.9972$, and the linear range is $5.0 \times 10^{-5} \sim 5.0 \times 10^{-3} \mathrm{~mol} / \mathrm{L}$.

Precision, Table 3 shows the precision experiment results of felodipine. It can be seen from the table that the relative standard deviation RSD of different concentrations of felodipine stock solution is less than $5.00 \%$, indicating that the method has good precision.
Table 3 Precision test results of detection of FEL

\begin{tabular}{|c|c|c|c|}
\hline $\begin{array}{l}\text { Concentrati } \\
\text { on/(10 } \\
\mathrm{mol} / \mathrm{L})\end{array}$ & measured value & $\begin{array}{c}\text { Average } \\
\text { measured value } \\
\text { mean } \pm \mathrm{SD} /\left(10^{-3}\right. \\
\mathrm{mol} / \mathrm{L})\end{array}$ & $\begin{array}{c}\mathrm{RSD} \\
/ \%\end{array}$ \\
\hline 0.5 & $\begin{array}{c}0.48 、 0.49 、 \\
0.51\end{array}$ & $0.493 \pm 0.015$ & 3.06 \\
\hline 3.0 & $\begin{array}{c}3.02 、 3.06 \text { 、 } \\
2.97\end{array}$ & $3.02 \pm 0.045$ & 1.49 \\
\hline 6.0 & $\begin{array}{c}6.12 、 5.94 、 \\
5.92\end{array}$ & $5.99 \pm 0.11$ & 1.83 \\
\hline
\end{tabular}

Accuracy, Table 4 shows the accuracy test results of felodipine. It can be seen from the table that the recovery rates of different concentrations of felodipine stock solution are (93.28 \pm 3.37$),(97.22 \pm 2.087)$, (96.5 \pm 1.58$)$, and the RSD values are $3.613 \%, 2.15 \%$, and $1.64 \%$, which are all less than $5.00 \%$. It shows that the method has good accuracy, and the recovery rate $(\%)=$ measured concentration/actual concentration $\times 100 \%$.

Table 4 Accuracy of ibuprofen $(n=3)$

\begin{tabular}{cccc}
\hline $\begin{array}{c}\text { Concentratio } \\
\mathrm{n} /(10-3 \\
\mathrm{mol} / \mathrm{L})\end{array}$ & $\begin{array}{c}\text { measured } \\
\text { concentration } \\
/(10-3 \mathrm{~mol} / \mathrm{L})\end{array}$ & $\begin{array}{c}\text { Recovery } \\
\text { mean } \pm \mathrm{SD} / \%\end{array}$ & $\begin{array}{c}\text { RSD } \\
/ \%\end{array}$ \\
\hline \multirow{4}{*}{0.5} & 96.71 & & \\
& 93.17 & $93.28 \pm 3.37$ & 3.613 \\
& 89.97 & & \\
\hline & 95.19 & & \\
& 99.36 & $97.22 \pm 2.087$ & 2.15 \\
& 97.12 & & \\
\hline & 96.35 & & \\
& 95.04 & $96.5 \pm 1.58$ & 1.64 \\
\hline
\end{tabular}

\subsection{Determination of sample content}

Table 5 shows the experimental results of felodipine sample content determination. It can be seen from the figure that there is no significant difference between the detection method used in this study and the labeled content of felodipine sustained-release tablets. The relative standard deviations of the two samples were measured at the same time. All are within the allowable range. In addition, this method and the pharmacopoeia method have no systematic errors, indicating that the method for detecting the content of felodipine in felodipine tablets constructed in this experiment is accurate and reliable. The content determination data of the sample is recorded as follows: 
Table 5 Determination of samples and comparison with the amount of annotation

\begin{tabular}{|c|c|c|c|c|c|}
\hline \multicolumn{4}{|c|}{ This method } & \multicolumn{2}{|c|}{ Pharmacopoeia } \\
\hline factory & $\begin{array}{l}\text { Detecti } \\
\text { on } \\
\text { Volum } \\
\text { e/mg }\end{array}$ & $\begin{array}{c}\text { labeled } \\
\text { amount/( } \\
\%)\end{array}$ & $\begin{array}{c}\text { RSD } \\
(\%)\end{array}$ & $\begin{array}{l}\text { Detecti } \\
\text { on } \\
\text { Volum } \\
\text { e/mg }\end{array}$ & $\begin{array}{c}\text { labeled } \\
\text { amount/( } \\
\%)\end{array}$ \\
\hline 1 & 100.6 & 100.12 & 1.5 & 99.7 & 99.72 \\
\hline 1 & 99.4 & 98.94 & 2.4 & 99.4 & 99.83 \\
\hline 2 & 99.2 & 98.89 & 1.9 & 98.5 & 99.64 \\
\hline 2 & 98.8 & 98.11 & 1.4 & 100.4 & 99.92 \\
\hline
\end{tabular}

\subsection{Exploration of reaction mechanism}

Figure 2 is a diagram of the possible binding mechanism of the complexes tetracyanoethylene and felodipine. Since tetracyanoethylene is a strong planar $\pi$ electron acceptor, felodipine (the $\mathrm{N}$ atom in the six-membered nitrogen-containing heterocyclic ring contains unbonded lone pairs of electrons) can be used as an electron donor, and tetracyanoethylene (as Electron acceptor) to form a $1: 1 \mathrm{n}-\pi$ type charge transfer complex.
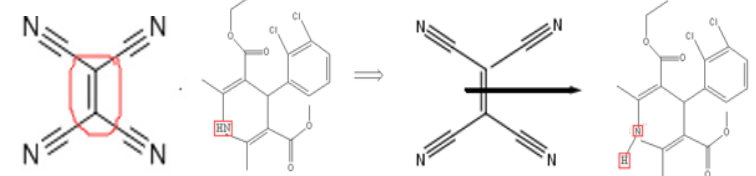

Figure 2 The reaction mechanism of felodipine and tetracyanoethylene

\section{Conclusion}

This experiment researched and constructed a complex with good fluorescence properties, which can be used to detect the content of felodipine. The actual sample of felodipine was successfully tested, and the test result was compared with the labeled content. It was proved that the content determined in this experiment was basically consistent with the standard content in the sample, and the reproducibility was good. Therefore, this method can be used to determine the content of felodipine in drugs, and even the content of felodipine in different substances, and it provides a new and reliable method for the determination of felodipine. The reaction conditions of this method are simple and easy to control, the operation is simple and fast, and the sensitivity is high.

\section{Acknowledgments}

This work was financially supported by the National Science Foundation of China (No.21346006), Basic scientific research project of Heilongjiang Provincial Colleges and Universities (No. 2020-KYYWF-0246), Excellent discipline team project of Jiamusi University ((No. JDXKTD-2019007).

\section{References}

1. de L e euw PW. A ntihyPertensive treatm entand the kidney[J]. C ardiovase D rugs T her, 2002, 16(6): 483-448.

2. Komers R, Anderson S. T reatmentofhy Pertension in diabetie Patients withne PhroPathy[J], Curr Diab ReP, 2001, 1(3): 251-260.

3. Swales P, Williams B. Calcium ehannel blockade in eombination with Angiotensin-onverting enzyme inhibition or angiotensin[AT receptor] antagonism in hyPertensive diabeties and Patients with renal disease and hypertension[J]. J Renin Angiotensin Aldosterone Syst, 2002, 3(2): 79-89.

4. Kuriyama S, Tomonari $\mathrm{H}$, Abe A, et al.Augmentation of antiproteinuric effect by combined therapy with angiotensin receptor bloeker plus calcium channel blocker in a hypertensive patient with $\operatorname{IgA}$ glomer-ulonephritis[J]. J Hum HyPertens, 2002, 16(5): 371-337.

5. Miao Yang, Yan Wang, Haiyan Wang. $\beta$-cyclodextrin func-tionalized CdTe quantum dots for electrochemiluminescent detection of benzo [a] pyrene [J]. Electrochim Acta, 2015, 169: 7-12.

6. MuRong Chao, Chiung Wen $\mathrm{Hu}$, Jian Lian Chen. Fluoromet-ric determination of copper ( II ) using CdTe quantum dotscoated with 1- ( 2-thiazolylazo ) -2-naphthol and an ionicliquid[J]. Microchim Acta, 2016, 183: 1323-1332.

7. Xiao Wei, Zhiping Zhou, Tongfan Hao, et al. Simple syn-thesis of thioglycolic acid-coated CdTe quantum dots asprobes for Norfloxacin lactate detection[J]. J Lumin, 2015, 161: 47-53. 